\title{
Sistem Informasi Peramalan Harga Pangan Dengan Menggunakan Metode Naïve Bayes Di Kota Makassar
}

\author{
Billy Eden William Asrul ${ }^{1}$, Sitti Zuhriyah ${ }^{2}$ \\ ${ }^{1}$ Stmik Handayani Makassar \\ ${ }^{2}$ Stmik Handayani Makassar \\ 1ㄹewagabriel@ymail.com
}

\begin{abstract}
Abstrak
Dinas Perdagangan Kota Makassar merupakan lembaga yang bertanggung jawab dalam merilis informasi harga pangan di Kota Makassar secara langsung. Informasi tersebut disajikan dalam bentuk selebaran. Penelitian ini bertujuan adalah untuk merancang dan menerapkan Sistem sistem informasi Peramalan Harga Komoditas Pangan Menggunakan Algoritma Naive Bayes untuk memprediksi harga pangan di Kota Makassar. Desain penelitian yang digunakan adalah UML yang didesain secara terstruktur yang terdiri dari rancangan model use case diagram, activity diagram, sequence diagram dan class diagram. Bahasa pemrograman menggunakan PHP, javascript, dan MySql untuk pengolahan database. Dalam penelitian ini pengumpulan data diperoleh melalui observasi, wawancara dan dokumentasi. Hasil dari penelitian ini adalah sistem berbasis website yang menyediakan informasi harga komoditas dan sistem pendukung keputusan prediksi harga komoditas pangan di Kota Makassar. Sistem tersebut membantu instansi dalam menyediakan informasi dan pelaporan.
\end{abstract}

Kata kunci : sistem pendukung keputusan, Sistem Informasi, Nä̈ve Bayes

\begin{abstract}
The Makassar City Trade Office is the agency responsible for releasing food price information in Makassar City directly. This information is presented in the form of leaflets. The aim of this research is to design and implement a Food Commodity Price Forecasting System using Naive Bayes Algorithm to predict food prices in Makassar City.
\end{abstract}

The research design used is UML which is structured designed which consists of the design of use case diagram models, activity diagrams, sequence diagrams and class diagrams. The programming language uses PHP, JavaScript, and MySQL for database processing. In this study data collection was obtained through observation, interviews and documentation. The results of this study are a website-based system that provides commodity price information and decision support systems for food commodity price predictions in Makassar City. The system helps agencies to provide information and reporting.

Keywords :Decision Support Systems, Naive Bayes, Information System

\section{PENDAHULUAN}


Pangan merupakan salah satu prioritas utama program pembangunan nasional karena memiliki nilai strategis terkait dengan kebutuhan masyarakat yang paling mendasar serta aspek ketahanan nasional, stabilitas ekonomi, stabilitas politik, dan keamanan. Dari aspek ekonomi pangan, harga merupakan salah satu aspek penting yang perlu mendapat perhatian. Penentuan harga pangan sangat penting terutama di tingkat petani sebagai produsen (dengan tetap melindungi konsumen), dengan tujuan melindungi petani kecil dari permainan harga.

Kurangnya informasi harga pangan dan perkiraan harga pangan yang terpercaya yang akan mempengaruhi para pelaku ekonomi ditingkat nasional dan daerah. Menimbulkan gejolak harga yang pada gilirannya dikhawatirkan dapat mempengaruhi stabilitas ekonomi makro. Ketidakjelasan dan kurang integritasnya informasi harga berpengaruh terhadap kestabilan harga pangan. Dinas Perdagangan Kota Makassar merupakan pihak yang menyediakan informasi harga pangan. Masyarakat ataupun pihak lain yang memerlukan informasi dapat mengunjungi Kantor Dinas Perdagangan Kota Makassar secara langsung. Informasi disajikan dalam bentuk selebaran. Namun informasi yang diberikan belum ada klasifikasi harga. Klasifikasi harga yang dimaksud adalah pembagian harga antara harga naik, harga turun, dan harga normal.

Dengan memperhatikan hal tersebut di atas, maka perlu dibuat sebuah sistem yang dapat memberikan informasi yang akurat mengenai hal-hal yang berkaitan dengan harga pangan. Oleh karena itu, Peneliti membuat suatu Sistem informasi peramalan Harga Komoditas Pangan Menggunakan Algoritma Nä̈ve Bayes di Kota Makassar. Seperti penelitian sebelumnya, sistem Prediksi harga daging sapi lokal di Kota Semarang[7], pada penelitian tersebut hanya menampilkan prediksi harga tanpa penjelasan harga naik, turun, atau normal,serta tidak menampilkan keadaan atau kondisi komoditas.Sedangkan Penelitian lain yang menggunakan metode Naïve Bayes adalah sistem pendukung keputusan menentukan lokasi rumah makan yang strategis menggunakan metode Naïve Bayes [8], pada penelitian tersebut dibuat suatu sistem untuk menentukan lokasi yang tepat dalam mendirikan sebuah rumah makan.

Sistem pendukung keputusan yang dibuat berbasis web dirancang dengan tujuan untuk memudahkan dan mengefisienkan kinerja dan aktifitas kerja serta memberikan gambaran umum tentang harga komoditas, kondisi komoditas pangan, dan prediksi harga barang.

Dalam pembuatan sistem ini digunakan metode Nä̈ve Bayes. Algoritma Naive Bayes merupakan pengklasifikasian dengan metode probabilitas dan statistik yaitu memprediksi peluang di masa depan berdasarkan pengalaman sebelumnya. Berdasarkan penjelasan tersebut maka penelitian ini akan membahas, bagaimana merancang sistem informasi Peramalan Harga Komoditas Pangan menggunakan Algoritma Nä̈ve Bayes di Kota Makassar?

\section{METODOLOGI PENELITIAN}

Metode penelitian yang diterapkan dalam mengembangkan Sistem Pendukung Keputusan peramalan harga komoditas pangan terdiri dari beberapa tahap.Dimulai dengan tahapan analisis kebutuhan sistem, perancangan desain sistem, pengujian, dan implementasi sistem.

Tahapan analisisi kebutuhan sistem hal pertama yang dilakukan adalah menentukan kebutuhankebutuhan sistem.Kebutuhan sistem terbagi menjadi dua yaitu fungsional yang meliputi kebutuhan user, kebutuhan administrator, dan pengujian.Sedangkan kebutuhan non-fungsional, meliputi kebutuhan perangkat keras dan kebutuhan perangkat lunak. Dalam tahapan analisis kebeutuhan juga mencakup pengumpulan data yang akan digunakan, yaitu data primer dan data sekunder. Data primer diperoleh dari wawancara langsung dengan pegawai Dinas Perdagangan Kota Makassar, sedangkan data sekunder diperoleh dari data yang sudah ada, terdiri dari data harga bahan pangan dari beberapa pasar yang ada di Kota Makassar.

Perancangan desain sistem bertujuan untuk memudahkan kinerja dan aktivitas kerja serta memberikan gambaran umum tentang bagaimana yang tepat untuk mendesain suatu system sesuai dengan kebutuhan instansi. Dalam tahap ini dibuat sebuah Use Case diagram yaitu sebagai berikut: 


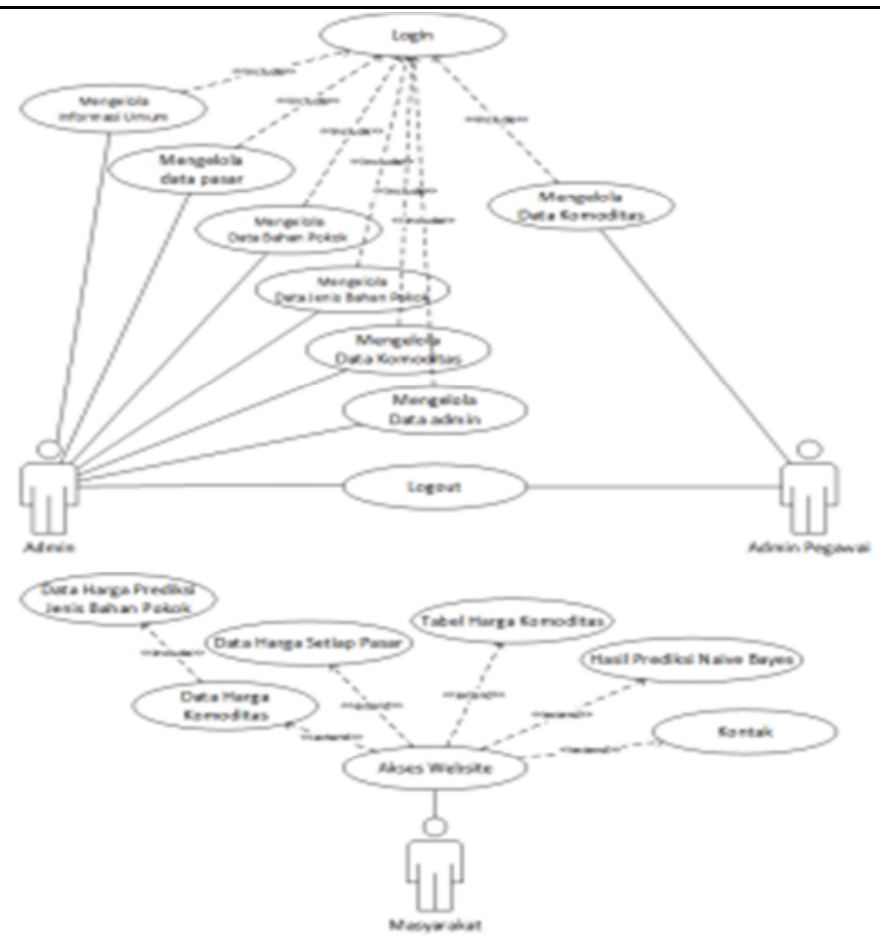

Gambar 1 Use Case Diagram

Dalam tahap perancangan sistem,algoritma yang digunakan adalah algoritma Naive Bayes untuk memprediksi harga naik atau turun suatu komoditas adalah metode Naïve Bayes, yang merupakan pengklasifikasian probabilistik sederhana yang menghitung sekumpulan probabilitas dengan menjumlahkan frekuensi dan kombinasi nilai dari, dataset yang diberikan[4]. Algoritma Naïve Bayes didasarkan pada asumsi penyederhanaan bahwa nilai atribut secara kondisional saling bebas jika diberikan nilai output. Keuntungan penggunaan Naïve Bayes adalah metode hanya membutuhkan jumlah data pelatihan ( training data ) yang kecil untuk menentukan estimasi parameter yang diperlukan dalam proses pengklasifikasian. Naïve Bayes sering bekerja jauh lebih baik dalam kebanyakan situasi dunia nyata yang kompleks dari pada yang diharapkan ( Alfa Saleh, 2015). Persamaan dari teorema Bayes adalah :

Di mana :

$$
P(H \mid X)=\frac{P(X \mid H) \cdot P(H)}{P(X)} \ldots \ldots \ldots(2)
$$

$X \quad$ : Data dengan class yang belum diketahui

$H \quad$ : Hipotesis data merupakan suatu class spesifik

$P(H / X) \quad$ : Probabilitas hipotesis $H$ berdasar kondisi $X$ (posteriori probabilitas)

$P(H) \quad$ : Probabilitas hipotesis $H$ (prior probabilitas)

$P(X / H)$ : Probabilitas $X$ berdasarkan kondisi pada hipotesis $H$

$P(X) \quad$ : Probabilitas $X$

Untuk menjelaskan metode Naïve Bayes, perlu diketahui bahwa proses klasifikasi memerlukan sejumlah petunjuk untuk menentukan kelas apa yang cocok bagi sampel yang dianalisis tersebut. Karena itu, metode Naïve Bayes di atas disesuaikan sebagai berikut:

$$
P\left(C \mid F_{1} \ldots F_{n}\right)=\frac{P(C) \cdot P\left(F_{1} \ldots F_{n} \mid C\right)}{P\left(F_{1} \ldots F_{n}\right)} \ldots \ldots
$$

Di mana Variabel $C$ merepresentasikan kelas, sementara variabel $F 1 \quad \ldots \quad F n$ merepresentasikan karakteristik petunjuk yang dibutuhkan untuk melakukan klasifikasi. Maka rumus tersebut menjelaskan bahwa peluang masuknya sampel karakteristik tertentu dalam kelas $C$ (Posterior) adalah peluang munculnya kelas $C$ (sebelum masuknya sampel tersebut, seringkali disebut prior), dikali dengan peluang kemunculan karakteristik-karakteristik sampel pada kelas $C$ (disebut juga likelihood), dibagi dengan peluang kemunculan karakteristik-karakteristik sampel secara global (disebut juga evidence). 


\section{HASIL DAN PEMBAHASAN}

Berikut merupakan implementasi prediksi harga naik atau turun dengan menggunakan algoritma Naïve Bayes

Tabel 3.1 data training Naïve Bayes

\begin{tabular}{|c|c|c|c|c|c|}
\hline No & $\begin{array}{c}\text { Kondisi } \\
\text { bahan } \\
\text { pokok }\end{array}$ & Cuaca & Persediaan & kendaraan & $\begin{array}{c}\text { Hasil } \\
\text { prediksi }\end{array}$ \\
\hline 1 & Baik & Baik & Banyak & Baik & Turun \\
\hline 2 & Baik & Baik & Banyak & Rusak & Turun \\
\hline 3 & Baik & Baik & Kurang & Rusak & Naik \\
\hline 4 & Rusak & Buruk & Kurang & Rusak & Turun \\
\hline 5 & Rusak & Baik & Banyak & Baik & Turun \\
\hline 6 & Rusak & Buruk & Kurang & Baik & Turun \\
\hline 7 & Baik & Buruk & Kurang & Rusak & Naik \\
\hline 8 & Baik & Buruk & Banyak & Baik & Naik \\
\hline 9 & Baik & Buruk & Banyak & Rusak & Naik \\
\hline 10 & Rusak & Baik & Banyak & Rusak & Turun \\
\hline 11 & Rusak & Buruk & Kurang & Baik & Naik \\
\hline
\end{tabular}

Sebagai contoh, Jika kondisi komoditas pangan dengan data sebagai berikut :

Table 3.2 contoh kondisi komoditas

\begin{tabular}{|c|c|c|c|c|}
\hline $\begin{array}{c}\text { Kondisi } \\
\text { bahan } \\
\text { pokok }\end{array}$ & Cuaca & Persediaan & $\begin{array}{c}\text { Kondisi } \\
\text { kendaraan }\end{array}$ & $\begin{array}{c}\text { Hasil } \\
\text { prediksi }\end{array}$ \\
\hline Rusak & Baik & Banyak & Baik & ??? \\
\hline
\end{tabular}

Dengan implementasi Naïve Bayes dalam Pemrograman PHP maka diperoleh :

\$bahan_pokok $=\$$ this->input->post('kondisi_bahan_pokok');

\$cuaca = \$this->input->post('cuaca');

\$kondisi_kendaraan $=$ \$this- $>$ input- $>$ post $($ 'kondisi_kendaraan');

\$persediaan $=$ \$this- $>$ input-> $\operatorname{post}($ 'persediaan');

Tahap 1 menghitung jumlah

$\mathrm{P}(\mathrm{Y}=$ Naik $)=5 / 11$ "jumlah data "Naik" pada kolom "Hasil Prediksi" dibagi jumlah data

$\mathrm{P}(\mathrm{Y}=$ Turun $)=6 / 11$ ' jumlah data "Turun" pada kolom "Hasil Prediksi" dibagi jumlah data

\section{Listing :}

\$naik=\$this->Naive_bayes_model->Count("WHERE keterangan='Naik'")->num_rows(); \$turun=\$this- $>$ Naive_bayes_model- $>$ Count("WHERE keterangan='Turun'")->num_rows(); \$total=\$this->Naive_bayes_model->Count("")->num_rows();

Tahap 2 menghitung jumlah kasus yang sama dengan kelas yang sama $\mathrm{P}($ Kondisi Bahan Pokok $=$ Rusak $\mid \mathrm{Y}=$ Naik $)=1 / 5$ "jumlah data Kondisi Bahan Pokok "Rusak" dengan hasil prediksi "Naik" dibagi jumlah data Naik $\mathrm{P}($ Kondisi Bahan Pokok = Rusak $\mid \mathrm{Y}=$ Turun $)=4 / 6$ "jumlah data Kondisi Bahan Pokok "Rusak” dengan hasil prediksi "Turun” dibagi jumlah data Turun

\section{Listing :}

\$bahan_pokok_naik= \$this->Naive_bayes_model->Count("WHEREｋondisi_bahan_pokok like '\$bahan_pokok' and keterangan='Naik'")->num_rows();

\$bahan_pokok_turun= \$this->Naive_bayes_model->Count("WHEREｋondisi_bahan_pokok like '\$bahan_pokok' and keterangan='Turun'")->num_rows();

$\mathrm{P}($ Cuaca $=$ Baik $\mid \mathrm{Y}=$ Naik $)=1 / 5$

jumlah data dengan Cuaca“Baik" dibagi jumlah data Naik

$\mathrm{P}($ Cuaca $=$ Baik $\mid \mathrm{Y}=$ Turun $)=4 / 6$

jumlah data dengan Cuaca"Baik" dibagi jumlah dataTurun 


\section{Listing :}

\$cuaca_naik= \$this->Naive_bayes_model->Count("WHERE cuaca like '\$cuaca' and keterangan='Naik"')$>$ num_rows();

\$cuaca_turun= \$this->Naive_bayes_model->Count("WHERE cuaca like '\$cuaca' and keterangan='Turun'")->num_rows();

$\mathrm{P}($ Persediaan $=$ Banyak $\mid \mathrm{Y}=$ Naik $)=2 / 5$

jumlah data dengan Persediaan "Banyak" dibagi jumlah data Naik

$\mathrm{P}($ Persediaan $=$ Banyak $\mid \mathrm{Y}=$ Turun $)=4 / 6$

jumlah data dengan Persediaan "Banyak" dibagi jumlah dataTurun

\section{Listing :}

\$kondisi_kendaraan_naik $=$ \$this->Naive_bayes_model->Count("WHERE kondisi_kendaraan like '\$kondisi_kendaraan' and keterangan='Naik'")->num_rows();

kondisi_kendaraan_turun $=$ \$this->Naive_bayes_model->Count("WHERE kondisi_kendaraan like '\$kondisi_kendaraan' and keterangan='Turun'")->num_rows();

$\mathrm{P}($ Kondisi Kendaraan $=$ Baik $\mid \mathrm{Y}=$ Naik $)=2 / 5$

jumlah data dengan Kondisi Kendaraan "Baik" dibagi jumlah data Naik

$\mathrm{P}($ Kondisi Kendaraan $=$ Baik $\mid \mathrm{Y}=$ Turun $)=3 / 6$

jumlah data dengan Kondisi Kendaraan "Baik" dibagi jumlah dataTurun

\section{Listing :}

\$persediaan_naik $=$ \$this->Naive_bayes_model->Count("WHERE persediaan like '\$persediaan' and keterangan='Naik'")->num_rows();

\$persediaan_turun= \$this->Naive_bayes_model->Count("WHERE persediaan like '\$persediaan' and keterangan='Turun'")->num_rows();

Tahap 3 kalikan semua hasil variable Naik dan Turun

$\mathrm{P}($ Kondisi Bahan Pokok = Rusak $),($ Cuaca $=$ Baik $),($ Persediaan $=$ Banyak $),($ Kondisi kendaraan $=$ Baik $) \mid$ Naik)

$=\{\mathrm{P}(\mathrm{P}($ Kondisi Bahan Pokok $=$ Rusak $\mid \mathrm{Y}=$ Naik $) . \mathrm{P}(\mathrm{Cuaca}=\mathrm{Baik} \mid \mathrm{Y}=$ Naik $) . \mathrm{P}($ Persediaan $=$ Banyak

$\mid \mathrm{Y}=$ Naik). $\mathrm{P}($ Kondisi kendaraan $=$ Baik $\mid \mathrm{Y}=$ Naik $)$

$=1 / 5 * 1 / 5 * 2 / 5 * 2 / 5 * 5 / 11$

$=0,0028$

$\mathrm{P}($ Kondisi Bahan Pokok = Rusak $),($ Cuaca $=$ Baik $),($ Persediaan $=$ Banyak $),($ Kondisi kendaraan $=$ Baik $) \mid$ Turun)

$=\{\mathrm{P}(\mathrm{P}($ Kondisi Bahan Pokok $=$ Rusak $\mid \mathrm{Y}=$ Turun $) . \mathrm{P}($ Cuaca $=$ Baik $\mid \mathrm{Y}=$ Turun $) . \mathrm{P}($ Persediaan $=$ Banyak $\mathrm{Y}=$ Turun $)$. $\mathrm{P}($ Kondisi kendaraan $=$ Baik $\mid \mathrm{Y}=$ Turun $)$

$=4 / 6 * 4 / 6 * 4 / 6 * 3 / 6 * 6 / 11$

$=0,077$

Listing :

$\$ \mathrm{p}=($ \$naik/\$total)*(\$bahan_pokok_naik/\$naik)*(\$cuaca_naik/\$naik)*(\$kondisi_kendaraan_naik/\$naik)*( \$persediaan_naik/\$naik);

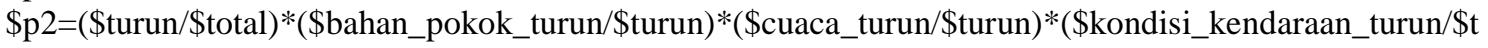
urun)*(\$persediaan_turun/\$turun);

\section{Tahap 4 bandingkan hasil Naik dan Turun}

Karena hasil (P|Turun) lebih besar dari ( $\mathrm{P} \mid$ Naik) maka keputusanya adalah"Turun".

if $(\$ \mathrm{p}>=\$ \mathrm{p} 2)\{\$ \mathrm{data}[$ 'keterangan'] = "Naik"; $\}$

else $\{$ data['keterangan'] = "Turun";

Tabel 3.3 Hasil Uji Komoditas

\begin{tabular}{|c|c|c|c|c|}
\hline $\begin{array}{c}\text { Kondisi } \\
\text { bahan } \\
\text { pokok }\end{array}$ & Cuaca & Persediaan & $\begin{array}{c}\text { Kondisi } \\
\text { kendaraan }\end{array}$ & $\begin{array}{c}\text { Hasil } \\
\text { prediksi }\end{array}$ \\
\hline Rusak & Baik & Banyak & Baik & Turun \\
\hline
\end{tabular}




\section{Implementasi pada Sistem}

Berikut beberapa contoh tampilan pada Website sistem peramalan harga dengan menggunakan metode Nä̈ve Bayes:

a. Login

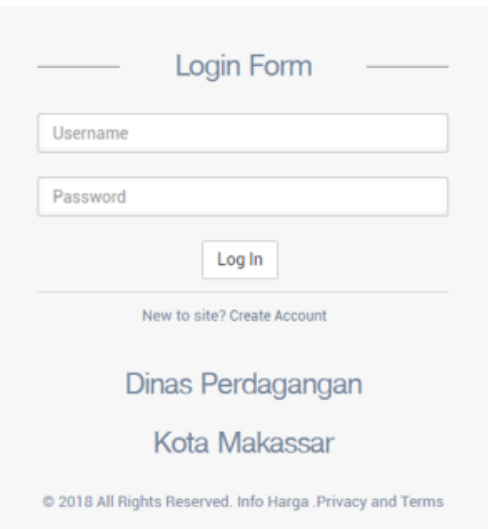

Gambar 3. 1 tampilan Login

Tampilan form login Admin tetapi juga merupakan form login untuk Pegawai.

b. Tampilan Menu Home

Tampilan Menu Home yang merupakan salah satu menu di tampilan utama untuk pengunjung.Menu ini bisa di akses atau di gunakan oleh pengunjung.berikut tampilan menu Home

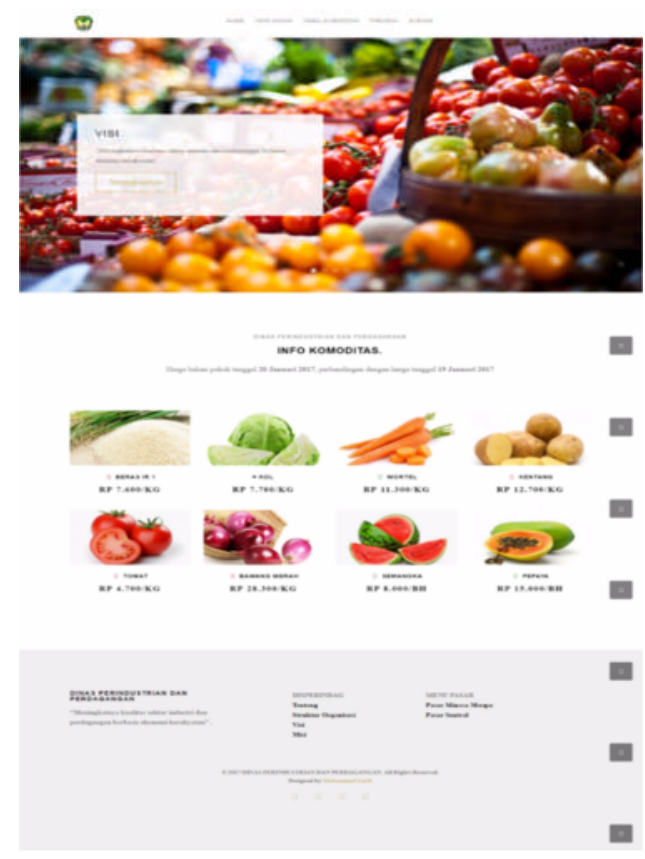

Gambar 3.2. Menu Home 
c. Menu Detail Bahan Pokok

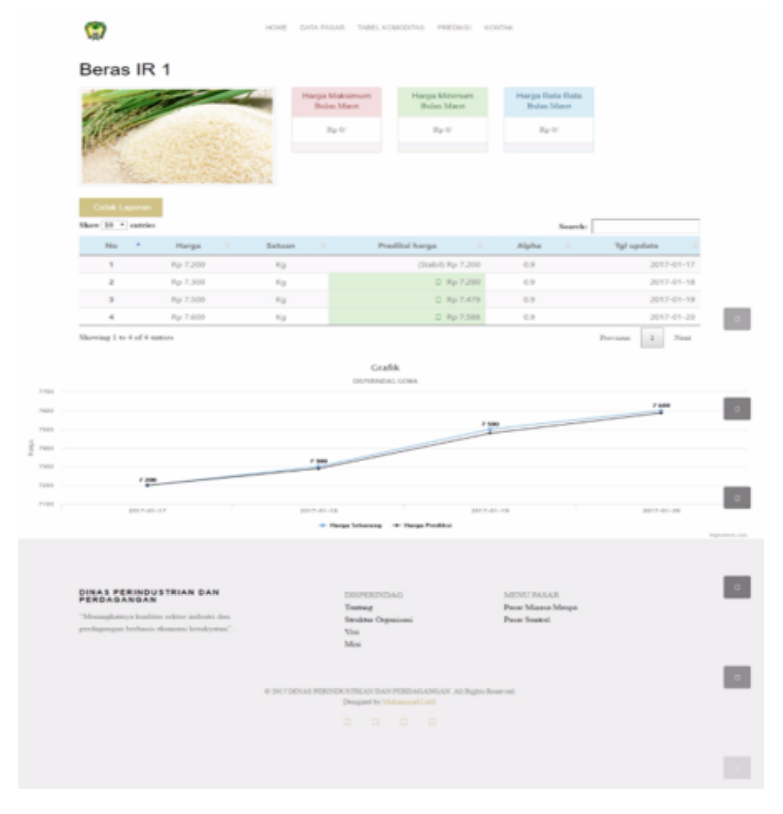

Gambar 3.3 Menu detail bahan pokok

Tampilan Menu detail bahan pokok yang merupakan salah satu menu di tampilan utama untuk pengunjung yang dapat diakses atau digunakan oleh pengunjung. Menu ini menampilkan prediksi harga salah satu komoditas secara detail.

d. Menu Tabel Komoditas

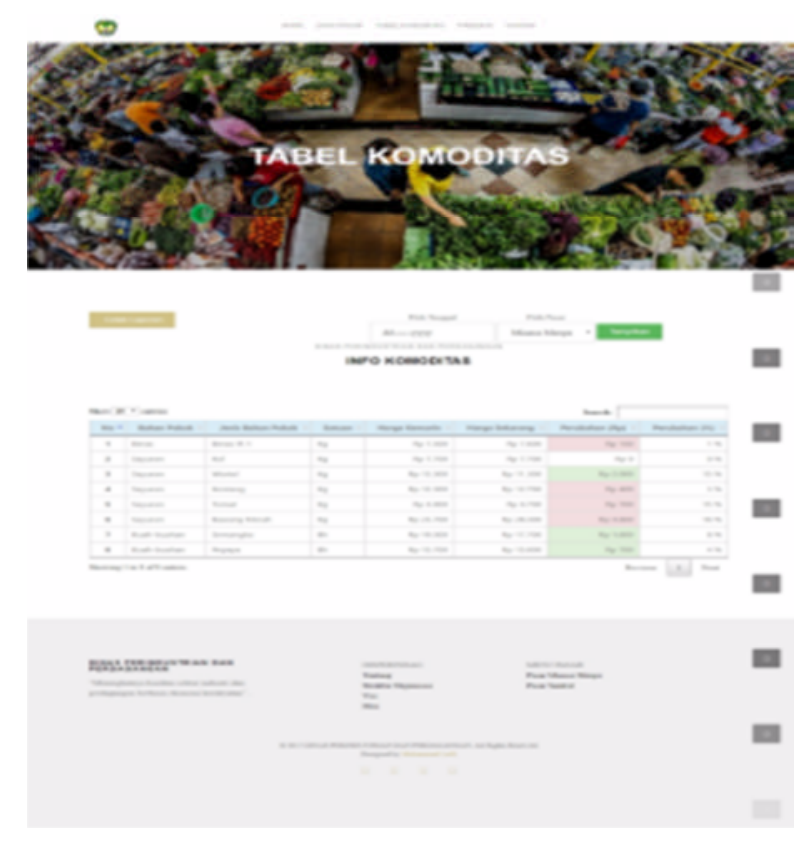

Gambar 3.4 Menu Tabel Komoditas

Tampilan Menu Tabel Komoditas yang merupakan salah satu menu di tampilan utama untuk pengunjung.Menu ini bisa di akses atau di gunakan oleh pengunjung. 
e. Menu Prediksi

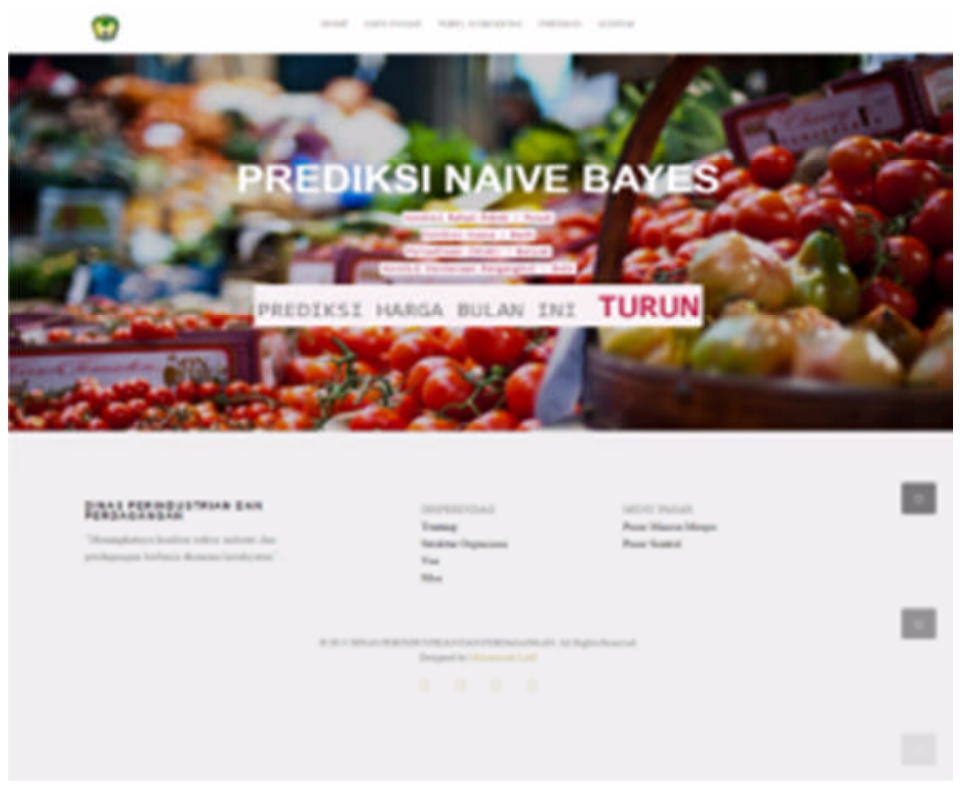

Gambar 3.5 Menu Prediksi

salah satu menu di tampilan utama adalah tampilan Menu Prediksi yang dapat diakses di gunakan oleh pengunjung, yang menampilkan prediksi harga barang komoditas, baik harga naik, turun ataupun normal.

\section{KESIMPULAN}

Agar sistem informasi peramalan Harga dapat lebih optimal maka Sistem yang dibuat berbasis web dirancang dengan tujuan untuk memudahkan dan mengefisienkan kinerja dan aktifitas kerja serta memberikan gambaran umum tentang harga komoditas, kondisi komoditas pangan, dan prediksi harga barang.

Dengan menerapkan sistem informasi Peramalan Harga Komoditas Pangan menggunakan Algoritma Nä̈ve Bayes di Kota Makassar, Masyarakat ataupun pihak lain yang dapat mengakses informasi tentang Klasifikasi harga yakni pembagian harga antara harga naik, harga turun, dan harga normal dengan mudah.

\section{UCAPAN TERIMA KASIH}

Terima kasih disampaikan kepada, para pelaku industri dan UMKM di lingkungan Kota Makassar, Dinas Perdagangan Kota Makassar, yang telah memberikan dukungan sehingga penelitian dapat terlaksana dengan baik, kepada Pimpinan dan rekan-rekan dosen di STMIK Handayani yang telah memberikan bantuan dalam penyelesaian penelitian ini.

\section{REFERENSI}

[1] Al Fatta.Hanif, “Analisis dan Perancangan Sistem Informasi”.Yogyakarta: Penerbit Andi, 2007

[2] Hermawan, "Unified Modelling Language (UML)". Yogyakarta: Penerbit ANDI, 2004

[3] Sari. Mega Kartika, "Kombinasi Metode K-Nearest Neighbor Dan Naïve Bayes Untuk Klasifikasi Data”.Yogyakarta: Prosiding SEMNASTEKNOMEDIA, STMIK AKAKOM, 2015.

[4]. Wasiati. Hera, "Sistem Pendukung Keputusan Penentuan Kelayakan Calon Tenaga Kerja Indonesia Menggunakan Metode Naive Bayes", IJNS-Indonesian Journal on Networking and security, Volume 3 No. 2 Tahun 2014. 
[5] Yuli, Ni Putu Sukmarani dkk, "Penerapan Metode Single Exponential Smoothing pada permalan penjualan dalam penentuan kuantitas Produksi Roti (studi Kasus Perusahaan Roti Dhiba Kendari)”, semanTIK, Vol.2, No.1, Jan-Jun 2016, pp. 229-236

[6] Margi, Kristen, “ Analisisi dan Penerapan Metode Single Exponential Smoothing untuk Prediksi Penjualan pada Periode Tertentu”, prosiding SNATIF ke-2 Tahun 2015

[7] Meysatya, Riska “Sistem Prediksi Harga Daging Sapi Lokal di Kota Semarang Menggunakan Moving Average”, Jurnal UDINUS, 2013.

[8]. Yusnita, Amelia, "Sistem Pendukung Keputusan Menentukkan Lokasi Umah Makan Yang Strategis Menggunakan Metode Naive Bayes", SEMANTIK, 2012. 